\section{RECURSOS DA TERAPIA NARRATIVA DE SESSÃO ÚNICA EM TEMPOS DE PANDEMIA E ISOLAMENTO SOCIAL}

\author{
RESOURCES FROM SINGLE SESSION NARRATIVE THERAPY \\ FOR TIMES OF PANDEMIC AND SOCIAL ISOLATION
}

RESUMO: Nesse texto, apresentamos as contribuições da modalidade de intervenção de terapia de sessão única fundamentada nos pressupostos da terapia narrativa aplicada ao contexto da pandemia da Covid-19. Iniciamos nosso texto com um esboço da complexidade que marca diferentes experiências da pandemia e isolamento social e apresentamos os principais cuidados a serem realizados no atendimento psicológico voluntário brevíssimo, on-line e em situação de emergências. Na sequência, abordamos 0 passo a passo da terapia narrativa de sessão única. Destacamos a importância da construção um uma agenda de trabalho para delimitação do foco da intervenção, da descrição rica e externalizada do problema, seus efeitos e sua influência na vida do cliente, da busca, reconhecimento e valorização de narrativas alternativas e, finalmente, da construção de possibilidades a partir dos recursos identificados na sessão. Acreditamos que o que apresentamos possa inspirar aplicações em variadas situações.

Palavras-chave: Terapia de sessão única; Terapia narrativa; Aconselhamento psicológico; Plantão psicológico; Emergências.

ABSTRACT: In this text, we present the contributions of single session therapy intervention based on the assumptions of narrative therapy applied to the Covid-19 pandemic context. We begin our text with an outline of the complexity that marks different experiences of the pandemic and social isolation and present the main aspects to be considered in very brief voluntary online psychological assistance in emergencies. In the sequence, we approach a step by step model of single session narrative therapy. We highlight the importance of building a work agenda to delimit the focus of the intervention, the rich and externalized description of the problem, its effects and its influence on the client's life, the search, recognition and appreciation of alternative narratives and finally the construction of possibilities from the resources identified in the session. We believe that the resources presented can inspire interventions in various situations.

Keywords: Single session therapy; Narrative therapy; Psychological counseling; Psychological duty; Emergencies.

RESUMEN: En este texto, presentamos las contribuciones de la modalidad de intervención en sesión única basada en los supuestos de la terapia narrativa aplicada en el contexto de la pandemia de Covid-19. Comenzamos con un resumen de la complejidad que marca diferentes experiencias de la pandemia y el aislamiento social y presentamos los principales cuidados a considerar en intervenciones muy breves de asistencia psicológica voluntaria, en línea y en emergencias. En la secuencia, abordamos el paso a paso de la terapia narrativa de una sesión única. Destacamos la importancia de construir una agenda de trabajo para delimitar el foco de la intervención, la descripción rica y externalizada del problema, sus efectos y su influencia en la vida del cliente, la búsqueda, el reconocimiento y la apreciación de narrativas alternativas y finalmente la construcción de posibilidades desde los recursos identificados en la sesión. Creemos que los recursos presentados pueden inspirar aplicaciones en diversas situaciones.

Palabras clave: Terapia de sesión única; Terapia narrativa; Asesoramiento psicológico; Guardia psicológica; Emergencias.

\section{LAURA VILELA \\ E SOUZA $^{1}$}
CAMILA MARTINS LION ${ }^{1}$

\section{LETÍCIA TROMBINI VIDOTTO ${ }^{1}$}

\section{MURILO DOS SANTOS MOSCHETA ${ }^{2}$}

\author{
${ }^{1}$ Faculdade de Filosofia, \\ Ciências e Letras \\ de Ribeirão Preto \\ Universidade de São Paulo, \\ Ribeirão Preto/SP, Brasil \\ ${ }^{2}$ Universidade Estadual \\ de Maringá, PR, Brasil
}

Recebido em 20/05/2020 Aprovado em 01/07/2020 


\section{INTRODUÇÃo}

Neste artigo, descrevemos a proposta do uso da terapia narrativa de sessão única como forma de atenção psicológica voluntária na situação da pandemia da COVID-19 e do isolamento social da população como medida de controle de sua disseminação. Este texto nasceu da construção que fizemos para uma conferência online com o mesmo título deste artigo, apresentado nas redes sociais de nossos laboratórios de pesquisa, o DIALOG (Laboratório de Pesquisas em Práticas Dialógicas e Colaborativas) da Universidade de São Paulo e DeVERSO (Grupo de Pesquisa em Sexualidade, Saúde e Política) da Universidade Estadual de Maringá, em 01 de maio de 2020.

Iniciamos nosso texto com um esboço da complexidade que marca diferentes experiências da pandemia e isolamento social. Em seguida, apresentamos de forma breve os principais cuidados a serem realizados no atendimento psicológico voluntário brevíssimo, on-line e em situação de emergências. Na sequência, abordamos a metáfora narrativa e a estrutura, finalidade e passo a passo da terapia narrativa de sessão única.

Acreditamos que esse material pode ser útil na situação atual de calamidade pública decorrente da crise sanitária e econômica na qual vivemos. Para além desse contexto, acreditamos que também pode ser instrumento para o uso da terapia de sessão única em outras situações, explorando seu caráter de acessibilidade ao atendimento psicológico e abertura para variadas necessidades das pessoas.

\section{ESBOÇANDO UMA COMPREENSÃO SOBRE 0 QUE NOS AFETA NESTE MOMENTO}

A pandemia da Covid-19 traz um conjunto complexo de fatores que nos afeta de modo variado e que pode produzir diferentes demandas para intervenções especializadas em saúde mental. Gostaríamos de delinear panoramicamente a complexidade dessas necessidades emergentes com fins de sinalizar os diversos cenários nos quais a terapia narrativa de sessão única pode vir a contribuir.

Uma via de entrada nessa reflexão pode abrir-se a partir da pergunta: Quem tem sido afetado por essa pandemia? Existem pessoas diretamente afetadas, ou seja, aquelas que contraíram o vírus e a doença e os familiares e cuidadores imediatamente a cargo delas. Para essas pessoas, as demandas de intervenção psicológica são aquelas relacionadas à experiência do adoecimento e do cuidado direto e envolvem o medo de morrer, de espalhar o vírus, de não conseguir cuidar, a culpa associada à transmissão e ao modo de contágio, as perdas e o luto, por exemplo.

Contudo, dado os impactos amplos e sistêmicos de uma pandemia, de um modo mais geral, todos/as somos indiretamente afetados/as por ela. Somos mobilizados/ as pelo temor ao adoecimento próprio ou de pessoas próximas, e temos nossas vidas modificadas pelas medidas de prevenção e controle da doença. O mundo não é mais como costumava ser e necessitamos redimensionar prioridades, rearranjar rotinas, redefinir expectativas, ajustar orçamentos, abandonar projetos e criar novos planos. São tarefas de reconstrução da vida nas quais intervenções concisas e urgentes podem ser de grande auxílio.

Em terceiro lugar, acreditamos que, do conjunto de pessoas afetadas, devemos destacar os/as profissionais de saúde e cuidado porque vivem esse momento desde o lugar de quem é convocado a exercer sua prática profissional com sentido de urgência e agravada responsabilidade, a despeito do medo, da ansiedade e muitas vezes da falta de recursos e condições para o desenvolvimento de seu trabalho.

Nova Perspectiva Sistêmica, v. 29, n. 67, p. 7-22, agosto 2020. 
Direta ou indiretamente, essas pessoas são afetadas (a) pela experiência própria da doença, (b) pelas medidas de controle da pandemia (da restrição de circulação e contato social, aos estudos, ao trabalho e à interrupção da produção de renda, quebra de rotinas, intensidade de informações e a necessidade de aprendizado de novos comportamentos) e (c) pelos desdobramentos da pandemia em amplas dimensões da vida social. Essas dimensões são:

- Culturais (incluem a emergência de novos sentidos, valores, temores, preconceitos)

- Sociais (a recomposição das formas de partilhar do espaço, de construir e manter vínculos, a sobrevalorização do espaço privado como espaço seguro, a mediação mais presente das tecnologias nos vínculos)

- Econômicas (a transformação nos padrões de consumo, nas formas de trabalho, a recessão econômica, a desaceleração do crescimento e a menor circulação do dinheiro)

- Políticas (o maior ou menor senso de segurança, amparo e responsabilidade coletiva que se constroem desde a percepção do modo como os governantes e figuras de autoridade pública reconhecem a gravidade da situação e agenciam os recursos do Estado para o seu enfrentamento)

- Existenciais (o questionamento acerca da vida e de seu valor, o redimensionamento de prioridades e a interrogação de princípios e crenças)

Quando consideramos a amplitude dessas dimensões podemos afirmar que a experiência de uma pandemia nos afeta de modo muito intenso, forçando a tomada de consciência de nossa vulnerabilidade. Essa vulnerabilidade deve ser entendida em dois sentidos, conforme nos ajuda a compreender Judith Butler (2015). Em um primeiro plano ela é uma marca compartilhada: somos todos/as vulneráveis porque podemos morrer e porque nossa sobrevivência está intrinsecamente ligada, por dependência, à existência de um outro (também vulnerável). Nesse sentido somos iguais. Mas sobre essa vulnerabilidade comum se instala socialmente uma política de alocação diferencial de recursos com a finalidade de potencializar ou minimizála, fazendo com que algumas vidas sejam percebidas como mais importantes, mais dignas de serem protegidas, cuidadas ou curadas. Nesse sentido não somos iguais. Essa dimensão jamais pode ser perdida de vista quando falamos da realidade brasileira. A pandemia ressalta as desigualdades históricas que compõem nossa condição social, resultado dessa política de maximização ou minimização de vulnerabilidades, que produzem diferenças incomensuráveis no modo como as pessoas são afetadas e de quais recursos dispõem para sobreviver e responder ao desafio desse momento. Por isso, entre o "quem é afetado" e "o que nos afeta" devemos incluir a consideração de "como somos afetados".

Gênero, raça, etnia, classe social, sexualidade, idade, habilidade física são marcadores capazes de amortecer ou exacerbar os efeitos da pandemia que, no jogo social, se materializam em distintas condições de vida concreta. Para dar apenas um exemplo, tomamos o gênero para considerar o modo muito diferente como homens e mulheres podem viver o isolamento social. Já se multiplicam nas redes sociais as notícias e relatos do aumento da violência doméstica contra mulheres nesse período. Também poderíamos nos perguntar sobre a negociação em torno da redistribuição do trabalho doméstico quando pais e mães ficam em casa, quando os filhos não vão à escola e quando o espaço familiar se transforma em home-office.

Esses elementos podem compor um momento de crise na vida de uma pessoa no qual ela sente que necessita de ajuda para prosseguir e busca por um cuidado especializado. Embora essa crise possa ser a ocasião na qual emerja a percepção da 
necessidade ou do desejo de iniciar uma psicoterapia, muitas vezes o pedido que se formula aqui é de uma intervenção muito pontual, focada em um conjunto de fatores específicos, frequentemente novos, e talvez temporários, que têm impedido a vida de continuar. É nesse cenário que pensamos que a terapia narrativa de sessão única tem a contribuir.

\section{PREPARANDO-SE PARA O ATENDIMENTO BREVÍSSIMO, ON-LINE E VOLUNTÁRIO}

A oferta voluntária de atendimento psicológico on-line na pandemia da COVID-19 tem sido nomeada por diferentes instituições como escuta, acolhimento, conversa, apoio. Em alguns momentos parece que essas nomeações servem para dar um caráter mais informal para esses atendimentos, como se a emergência da situação justificasse uma maior flexibilidade nas normas que se colocam para o trabalho cotidiano do/a psicólogo/a em situações não emergenciais. Porém, toda e qualquer intervenção, independentemente de sua duração ou objetivo, mesmo que sem fins psicoterapêuticos, é uma intervenção profissional do/a psicólogo/a e, portanto, deve responder a todos os preceitos éticos e regulamentações do Sistema Conselho de Psicologia.

Quando ouvimos os/as profissionais que trabalham nas estratégias de prevenção e enfrentamento de emergências e desastres aprendemos que essas situações pedem o oposto da pressa, improviso e informalidade. O que esses/as profissionais nos contam é sobre o prejuízo de ações que não são pensadas de forma planejada, articulada e sustentável no pós-emergência (Conselho Regional de Psicologia de São Paulo- CRPSP, 2016).

Assim, aprendemos com esses/as especialistas que uma ação voluntária ideal nesse momento é aquela que busca conhecer as iniciativas do território e se integrar a elas, que pensa sua colaboração como articulada às ações dos/as profissionais de saúde mental das redes públicas e que antecipa as formas de encaminhamento das pessoas com quem nos dispomos a conversar. Ou seja, eticamente temos o compromisso de, ao reconhecer o limite de nossa oferta de ajuda, saber como encaminhar para outros serviços a pessoa por nós acolhida que se encontra ainda precisando de outros cuidados. Assim, respondemos ao que propõe a Nota Orientativa às(aos) Psicólogas(os) sobre o trabalho voluntário e Publicidade em Psicologia, diante do Coronavírus (COVID-19), sobre a necessidade de que o/a profissional tenha "uma proposta de trabalho com início, meio e fim, ou que garanta a gratuidade por todo o período de prestação do serviço" (Conselho Regional de Psicologia - CRP, 2020).

Da Resolução do Conselho Federal de Psicologia 001/2009, sabemos que temos a obrigatoriedade do registro documental de toda prestação de serviço psicológico que realizarmos. Isso se aplica aos atendimentos voluntários realizados na pandemia. Devemos manter esses registros conosco, no caso de profissionais autônomos, ou em nossas instituições de pertença, por no mínimo cinco anos (Conselho Federal de Psicologia - CFP, 2009). É também importante conhecermos sobre "Primeiros cuidados psicológicos" a partir, por exemplo, do guia produzido pela Organização Pan-Americana da Saúde (2015), que aponta as reações psicológicas esperadas nessas situações, sobre intervenção em crise, sobre transtornos de estresse traumático e primeiros socorros em uma intervenção psicossocial.

Seguindo o código de ética do/a psicólogo/a, não podemos utilizar a gratuidade de nossos atendimentos como meio de divulgação. A orientação do Conselho Regional de Psicologia de São Paulo (2020) é a de que se utilize o termo "atendimento emergencial voluntário" quando formos falar de nossa oferta de trabalho. 
O isolamento social também nos faz ter a necessidade de saber sobre os cuidados no uso das tecnologias de atendimento virtual, o que implica conhecer seus aspectos éticos, técnicos e de segurança. Com relação ao atendimento on-line, temos a Resolução n. 11/2018, do Conselho Federal de Psicologia (2018), que orienta a categoria sobre a prestação de serviços psicológicos realizados por meios de tecnologias da informação e da comunicação. Desde o início da pandemia muito tem se falado sobre a segurança do uso dos aplicativos comerciais para atendimento on-line de pacientes e clientes, de forma a garantir o sigilo e confidencialidade das conversas. Já soubemos de um programa que teve vazamento de dados e das dificuldades de termos certeza de qual é o acesso que o aplicativo tem e o uso que faz das informações compartilhadas. A importância de um ambiente virtual seguro tem sido endossada para que não menosprezemos o risco que a sobrecarga na rede pode oferecer e o interesse que o fato de todos nós estarmos usando a internet de forma maciça em nossas comunicações pode despertar em hackers mal intencionados.

A Resolução do Conselho Federal de Psicologia (2018) aponta que o atendimento on-line é condicionado ao cadastro do/a psicólogo/a no site "Cadastro e-Psi" (link: https://e-psi.cfp.org.br/). Nesse cadastro, o/a psicólogo/a deve informar qual plataforma de comunicação on-line vai utilizar e quais cuidados estará implementando para garantir o sigilo de suas intervenções. Em função da pandemia, o Conselho Federal de Psicologia (2020), em sua resolução 04, de 26 de março de 2020, afirma que, temporariamente, não é necessário aguardar a confirmação da plataforma para iniciar os atendimentos (CFP, 2020).

A resolução 11/2018 dispõe também sobre os atendimentos em situação de urgência e emergência. Aponta que esses atendimentos não devem ser realizados por meios de tecnologia e informação, devendo ser executados por equipes de forma presencial. No início do uso das estratégias de distanciamento social, o Sistema Conselhos ainda reafirmava o impedimento de realização de atendimento virtual com pessoas em situações de emergência, afirmando que as "situações de urgência e emergência (acolhimento imediato em situação de crise) devem preferencialmente ser atendidas de forma presencial por profissional ou equipes habilitadas para manejo de crise" (CFP, 2020). Todavia, também em função da pandemia, no dia 26 de março, o Conselho Federal de Psicologia (2020) lançou resolução que suspende os artigos da resolução 11/2018 que proíbem o atendimento on-line nessas situações.

As ressalvas do Sistema Conselhos são justificáveis, pois o atendimento on-line de pessoas em situações de crise exige o conhecimento de um protocolo de ação no caso de a pessoa estar em situação de risco ou violência. Nesses casos, alguns cuidados podem ser tomados. O primeiro deles é coletar os dados pessoais da pessoa atendida, com informações de contatos e com a indicação de um contato de emergência que more na cidade da pessoa e que possa ser acionado em caso de necessidade. Ainda, torna-se importante conhecer os serviços de atendimento de urgência que a pessoa pode acessar, o que a territorialização dos atendimentos e integração com a rede pública garante com maior facilidade.

\section{O POTENCIAL DA ABORDAGEM NARRATIVA}

A oferta de estratégias de atendimento pontual às pessoas que se encontram em sofrimento emocional em função da pandemia nos leva à necessidade de conhecermos sobre as modalidades de atendimento psicológico brevíssimo. Dentre essas estratégias está a terapia de sessão única. 
A terapia de sessão única, do inglês single session therapy, é utilizada há décadas em diversos países e estudada de forma mais sistemática nos últimos anos em seus potenciais terapêuticos. A nomenclatura foi cunhada por Moshe Talmon em 1990. Segundo essa definição, não se trata de oferecer apenas um dia de uma psicoterapia convencional, mas sim de realizar um processo completo em si mesmo e com propósitos específicos compatíveis com uma intervenção única.

Tomada como uma modalidade de atendimento, a terapia de sessão única é realizada por profissionais de diferentes abordagens teóricas. Todavia, em comum, todas seguem alguns pressupostos: foco pragmático do atendimento, foco na necessidade imediata da pessoa, busca de reconhecimento dos recursos da pessoa e de sua rede de apoio, foco nas habilidades, conhecimento e competências da pessoa para lidar com a situação-dilema: resgate das histórias passadas de superação de dificuldades, posicionamento do/a cliente como especialista sobre como agir para lidar com o problema (Hoyt et al., 2018).

Nosso uso da terapia de sessão única parte da perspectiva narrativa que investe na forma como estruturamos a conversa para a criação de novos sentidos. A perspectiva narrativa foi adaptada por Karen Young (2018), assistente social canadense do Windz Institute, para seu uso em terapia de sessão única. Karen teve em seu percurso variadas interlocuções com Michael White e David Epston, criadores da terapia narrativa. Devemos a ela nosso aprendizado e inspiração para trazermos sua proposta para o contexto brasileiro.

Relataremos sobre o nosso modo de fazer terapia narrativa de sessão única (TNSU) com adultos (Souza et al., 2018) e apresentaremos um recorte dos recursos que notamos como sendo os mais potentes para o contexto atual. Cabe mencionar que reconhecemos que os conceitos acionados pela terapia narrativa possuem uma ampla sustentação teórica. No entanto, apresentar esse aprofundamento teórico não é nosso objetivo neste texto.

Ao fazer uso da metáfora narrativa, podemos compreender que os dilemas apresentados pelas pessoas estão e são construídos na linguagem, portanto, não são vistos como estando dentro das pessoas. É por meio das histórias que as pessoas contam e recontam ao se relacionar com outras pessoas, levando em conta os aspectos históricos, sociais e culturais, que os sentidos atribuídos às experiências são construídos e descritos como problemáticos ou não (Morgan, 2007).

Considerando esse entendimento, as práticas narrativas oferecem ferramentas conversacionais que auxiliam na exploração de histórias que podem nunca terem sido contadas acerca do problema ou da experiência vivida e de ações em que as pessoas se engajam para responder a isso, que geralmente estão conectadas aos valores, crenças e propósitos que elas possuem. Alguns exemplos dessas ferramentas são a externalização, a re-autoria e a remembrança (re-membering) (White, 2007). De forma breve, apresentamos essas ferramentas:

Externalização: em nossa sociedade é comum que as pessoas compreendam os problemas como estando dentro delas e/ou como sendo representativos de que há algo em seu jeito de ser que não vai bem. Em oposição a isso, o conceito de externalização nos oferece norteadores para a construção de perguntas que buscam estimular a construção de histórias que colaborem para separar a identidade das pessoas de narrativas problemáticas e, assim, possibilitar a produção de novos modos de compreensão e ação perante o problema ou situação vivida.

Re-autoria: é uma prática que se baseia na ideia de que não é possível descrever a identidade ou a experiência das pessoas por meio de uma única história, pois histórias únicas podem limitar a riqueza e complexidade da experiência vivida e as possibilidades identitárias. Diante disso, há a crença de que, para cada história 
contada, há muitas outras que estão silenciadas e que podem estar compostas de ações, pensamentos, momentos que contradizem a história dominante contada sobre o problema, sobre a experiência vivida ou sobre si mesmo.

Essas histórias não contadas são consideradas como sendo histórias alternativas e entende-se que elas podem ser construídas na conversa por meio de perguntas direcionadas às experiências vividas que não ganharam notoriedade anteriormente. Considerando isso, a re-autoria nos oferece norteadores para associar esses acontecimentos a outras experiências e, assim, ajudar no processo de transformação desses acontecimentos, para que tenham maior relevância e se tornem menos vulneráveis e mais consistentes.

Remembrança: inspirado pelas ideias da antropóloga Barbara Myerhoff, Michael White introduz o conceito de Remembrança (re-membering) ao contexto de terapia, compreendendo, a partir da metáfora de 'clube da vida', que cada pessoa possui um grupo de membros que compõe esse clube e que, por meio de diferentes ações e falas, molda o modo da pessoa atuar e viver. É mais que um recordar, é um retomar e reorganizar quem são os membros (podendo ser pessoas vivas ou falecidas, personagens, animais, entre outros) que fazem parte da vida da pessoa e ajudam a moldar quem ela é, no que acredita e o que quer para sua vida, sendo que o grau de importância e influência desses membros pode ser diferente e se alternar com o passar das experiências. Deste modo, essas ideias enfatizam o entendimento de que o self é construído nas relações e não é algo estático. Considerar tais ideias estimula a realização de perguntas que buscam reconhecer as pessoas que compõem o clube da vida do/a nosso/a cliente e, assim, compreender se é necessário reorganizar o grupo de associados deste clube e suas funções.

No esquema a seguir apresentamos o panorama das quatro etapas da conversa da terapia narrativa de sessão única, que entendemos ser importantes de serem percorridas em um atendimento no contexto de pandemia e isolamento social. São elas: (a) Construção da agenda, (b) Conhecendo os efeitos do problema, (c) Buscando histórias de recursos e, por fim, (d) Construindo possibilidades futuras.

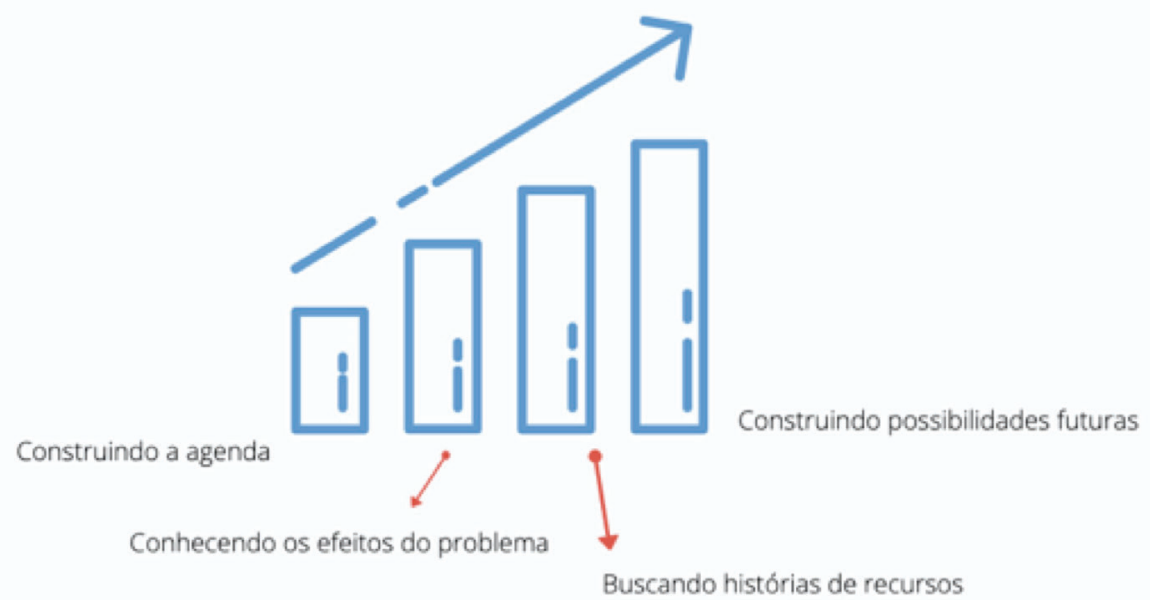

Michael White (2007), inspirado pelas ideias de Vygotsky, principalmente no que se refere ao entendimento do desenvolvimento como originário da aprendizagem, nomeia esse processo que aqui chamamos de etapas como uma conversa de construção de andaimes, pois é uma trajetória conversacional que se inicia por algo já familiar 
à pessoa em direção à construção de novas possibilidades e histórias, sempre de um modo sensível ao ritmo construído com o/a cliente (Grandesso, 2011; White, 2007).

Cabe mencionar que não há um jeito único de passar por essas etapas e nem uma duração específica para explorar cada uma delas. Muitas vezes pode acontecer um movimento de ir e vir entre elas. Como cada cliente é único/a, com alguns será possível passar por todas etapas, com outros não. O mais importante é construir junto com o/a cliente os caminhos que parecem ser mais úteis de serem explorados na conversa. Esse processo é para inspirar e nortear o diálogo, portanto, não deve ser utilizado como um passo a passo a ser seguido rigidamente.

Por desejarmos que a conversa produza uma novidade que seja significativa para a pessoa, temos que cuidar da forma como conversamos. Um recurso para esse cuidado é a construção do contexto conversacional (Rasera \& Japur, 2005; Vicente et al., 2015), por meio do qual é possível negociar aspectos do "como" a conversa pode acontecer, sobre "o que" vai ser falado e o "para quê" a conversa, ou seja, os propósitos do atendimento.

Em momentos de crise ou de situações desafiadoras, é comum que, enquanto profissionais, nos sintamos unicamente responsáveis por encontrar algum modo de resolver a situação da pessoa que nos procura, bem como assumir uma posição de urgência a partir da compreensão de que há um jeito certo ou ideal para solucionar o problema. Entendemos que essas são crenças culturais relacionadas ao que é esperado do/a profissional, no entanto, ficar conectado com tais crenças pode fazer com que deixemos de atuar de modo colaborativo com o/a cliente e com que, em muitos momentos, nos sintamos impotentes perante as angústias apresentadas por ele/a (Buckley \& Decter, 2006). Nesse sentido, na construção do contexto da conversa, podemos explicar para a/o cliente que nosso papel não será de resolver seus problemas, mas sim ampliar as possibilidades de entendimentos, de sentimentos e de ações.

Costumamos dizer para o/a cliente que trabalhamos de modo colaborativo e com perguntas, sendo estas um convite e não um inquérito. Assim, oferecemos a/ao cliente a possibilidade de escolha em respondê-las ou não, considerando importante ele/a estar à vontade para decidir quais aspectos da sua vida vai desejar compartilhar em uma única conversa. Vale mencionar também que, em alguns momentos, ofertamos entendimentos e aspectos que nos chamaram atenção na conversa e que podem ou não fazer sentido para ele ou ela. Consideramos ainda mais importante compreender com o/a cliente: o que poderia te ajudar a ficar confortável na conversa? Ao abordar esse aspecto, conseguimos atribuir o tom que desejamos construir na intervenção.

\section{ETAPA 1: CONSTRUINDO A AGENDA}

Esse é um momento muito importante do processo, pois perguntaremos para a pessoa o que ela está esperando da conversa e isso nos ajuda a compreender tanto a prioridade do/a cliente naquele momento, quanto construir norteadores para podermos avaliar o atendimento ao final. Perguntas que nos ajudam a construir a agenda incluem:

- Pensando que temos uma hora e meia para estarmos juntos, sobre qual situação, problema, dilema você gostaria de conversar hoje?

- O que você precisa que aconteça para que você saia daqui hoje sentindo que essa conversa foi útil ou que valeu a pena nosso encontro? 
- Temos, então, que escolher com o/a cliente a prioridade. É comum as pessoas contarem diferentes problemas/angústias/preocupações sobre uma variedade de temas. Se isso acontecer, é importante convidá-lo/a a escolher um e dizer que essa escolha pode ser checada durante o atendimento:

- Você poderia me falar quais dessas coisas que você falou estão te deixando mais preocupada, angustiada no momento?

É interessante que, em alguns atendimentos, tivemos feedback de que só o fato de auxiliarmos na organização de tudo o que ela está vivendo, no sentido de desemaranhar esses problemas, já foi algo importante para auxiliá-la a identificar quais seriam os primeiros passos que poderiam dar a partir dali. Nesse sentido, é importante ter paciência e dispor de tempo para investir nessa etapa, entendendo que o esforço empregado aqui tem potencial de produzir efeitos terapêuticos mesmo que não haja tempo para realizar todas as quatro etapas do processo.

\section{ETAPA 2: CONHECENDO OS EFEITOS DO PROBLEMA}

Antes de adentrarmos esta etapa, é muito importante compreender se as necessidades básicas da pessoa (em relação à alimentação, à moradia, à saúde, à segurança) estão sendo supridas. Pois, se ela não tem todas as necessidades supridas, isso se torna um tema prioritário para a conversa. Portanto, será necessário compreender sua situação e auxiliá-la a ter acesso aos serviços que estão disponíveis para que ela tenha seus direitos básicos assegurados.

Sustentadas pelas ideias da terapia narrativa, entendemos que quando as pessoas vão a um atendimento terapêutico costumam apresentar uma narrativa dominante que geralmente é composta pela história do problema, das dificuldades, angústias, bem como visões limitadas sobre a situação que está vivendo ou em relação à sua identidade, a qual costuma estar bastante conectada com o problema. É comum que em suas narrativas sobre seus problemas as pessoas os descrevam como fazendo parte de seu modo de ser, isto é, a pessoa pode estar olhando para si como sendo o problema. Nesse sentido, nessa etapa da conversa, partimos da ideia da terapia narrativa (White \& Epston, 1990) de que a pessoa é a pessoa e o problema é o problema, por isso, fazemos perguntas que ajudam a externalizar o problema, isto é, separá-lo da visão totalitária de que a pessoa pode estar tendo de que o problema está dentro dela. Nesse sentido, convidam-se aspectos macrossociais para a conversa, visando à construção de uma visão alternativa ao pensamento ocidental presente em nossa cultura, que possui um olhar de déficit sobre o indivíduo (Drewery \& Winslade, 1997).

Realizamos isso por meio de perguntas que convidam a uma descrição detalhada do problema e de como ele tem afetado as diferentes áreas da vida da pessoa: familiar, social, amorosa profissional, escolar e até mesmo a visão que ela tem de si mesma diante do problema.

No caso específico da pandemia, compreendemos que ela é um problema coletivo e externo ao indivíduo, por isso, nesse momento, o foco das perguntas será em conhecer quais são os efeitos que esse atual cenário está gerando na vida dessa pessoa. Dito isso, perguntamos sobre a história do problema, mas de um jeito que ajuda a separar a pessoa (identidade) em relação ao problema:

- Como você chamaria esse problema que você está vivendo?

- Você pode me falar mais dele? Descrevê-lo? O que ele faz? Quando ele aparece? 
- Se esse problema fosse uma criatura, um bicho, uma coisa, a que se pareceria?

- Como ele tem afetado sua relação em casa, com sua família, com seu trabalho, com seus relacionamentos?

- Como esse problema tem impactado na forma como você vê a si mesmo?

- Que regras o problema está tentando impor em sua vida? O que ele está fazendo você fazer ou deixar de fazer?

Como exemplo, poderíamos imaginar uma pessoa cujo problema que está vivendo é denominado de ansiedade. Ela descreve que sempre foi uma pessoa ansiosa, mas que agora isso se intensificou, pois não pode sair de casa. Essa ansiedade aparece principalmente pela manhã quando abre o site de notícias e faz seu coração acelerar, traz uma sensação ruim, um aperto no peito e desesperança. Quando pensa em alguma imagem que representa esse problema, ela imagina que ele se parece com "uma mão esmagadora de corações" que tem afetado sua vida de modo geral, fazendo com que ela tenha dificuldades de encontrar sentido nas coisas do dia a dia. Isso a tem deixado com menos paciência e mais sensível em suas relações, o que tem ocasionado algumas brigas familiares. Além disso, "a mão esmagadora" a tem deixado sem esperanças, a faz se sentir pessimista e uma péssima pessoa para se conviver nessa quarentena.

Algumas perguntas que ajudam a explorar os efeitos do problema:

- De que formas o problema precisa que você pense/sinta para que ele continue a existir?

- O que você imagina que aconteceu para esse problema passar a ter tanta influência sobre você?

- Como ele consegue se aproveitar disso?

- O que esse problema está querendo para sua vida é o mesmo que você quer? O que você quer para sua vida?

Esse momento de compreender as histórias do problema na vida da pessoa pode, em algumas situações, trazer a sensação de que estamos patinando e entendemos que essa sensação pode estar conectada com a lógica de que há algo na história do problema que necessita ser descoberto e, assim, a solução ser encontrada. No entanto, a nossa compreensão é de que a terapia narrativa nos convida a apostar não no movimento de vasculhar os problemas em busca de uma resposta, mas sim explorar uma descrição mais detalhada da atuação do problema e dos seus efeitos, para que essas informações possam ajudar a construir histórias novas acerca da relação da pessoa com o problema, auxiliando para que a pessoa tenha mais agenciamento sobre ele. $\mathrm{O}$ fundamental é construir uma linguagem que explore a relação da pessoa com o problema, ou seja, uma linguagem que não presuma que o problema seja a pessoa, mas sim um aspecto com o qual ela se relaciona.

Compreendemos que esse movimento nos ajuda, enquanto terapeutas, a estarmos mais atentos/as a qualquer detalhe novo que aparece na história do problema e não necessariamente em ficar buscando soluções ou nos cobrando para encontrá-las. As soluções vão sendo construídas à medida que a história do problema vai sendo percebida a partir de uma nova perspectiva.

Além disso, em muitos casos, tendo em vista as ideias foucaultianas, reconhecemos que muitas narrativas de problema são produzidas com base nos discursos que são produzidos pela sociedade e que definem normativamente a vida (Foucault, 1996). Neste contexto atual de pandemia, por exemplo, nos deparamos com: os discursos da produtividade, tanto profissional quanto em relação a cuidados com 
o bem-estar - de que se tem que 'aproveitar' o período em casa, realizar atividade física, ter uma alimentação saudável e/ou sair da quarentena tendo aprendido algo novo; os discursos relacionados à patologização - se a pessoa está comendo mais durante o isolamento, ela tem compulsão alimentar ou se a pessoa está entristecida, ela necessariamente desenvolveu uma depressão, entre outros discursos que vão produzindo normas e modelos de vida, identidade e papéis ideais.

Para explorar os discursos sociais que sustentam as descrições do problema, podemos perguntar, inspirados em Jill Freedman e Gene Combs (comunicação pessoal, 2018):

- Não acho que essa forma de se pensar/agir/sentir/lidar foi inventada por você. Como você aprendeu? Onde? Com quem?

- O que essa forma de pensar te faz sentir enquanto (papéis sociais exercidos)?

- Existem expectativas/pressões/padrões sociais envolvidos na construção desse problema?

- Como as coisas seriam nesse período de pandemia se não existisse essa expectativa/pressão/padrão?

É importante ressaltar que, nos atendimentos, também podem aparecer narrativas que envolvem vivências de violência e abuso. Essas narrativas demandam uma atenção especial e devem tornar-se temas prioritários da conversa para garantia da segurança da pessoa.

\section{ETAPA 3: BUSCANDO HISTÓRIAS DE RECURSOS}

Este é o momento de conhecer as narrativas alternativas, que são os aspetos da história que não aparecem na narrativa dominante e que podem ampliar os entendimentos acerca do problema, da identidade ou da situação vivida. Essas narrativas se alimentam da exploração dos aspetos de exceção, isto é, momentos ou esferas da vida da pessoa em que o problema não está presente ou que a situação vivida pode ser compreendida por meio de um outro entendimento. Para a perspetiva construcionista social, a linguagem, entendida como performance corporificada, constrói realidades. Assim, há a ênfase na exploração de em que medida a forma como narramos os problemas circunscreve as formas de superá-lo.

Cabe mencionar que esse não é um movimento ingênuo de identificação de aspetos positivos para a construção de uma mensagem de otimismo ou de negação dos aspetos materiais, relacionais e sociais que envolvem as dificuldades concretas na vida das pessoas. $\mathrm{O}$ foco é na identificação dos valores, crenças, habilidades e intenções que se encontram "nas sombras", nas palavras de Karen Young, ou seja, aspetos não iluminados em função da dominância das narrativas sobre o problema. A partir dessa identificação, novas narrativas podem ser tecidas servindo como recursos potentes para lidar com a situação dilemática, favorecendo maior agenciamento da pessoa frente ao entendimento dominante que estava lhe paralisando.

Esta se torna uma etapa muito importante no atendimento de terapia de sessão única, pois temos percebido que explorar a história dos recursos, valores, propósitos, colabora para dar visibilidade a pontos valiosos na vida da pessoa que não foram afetados pelo problema e que ajudam a sustentar quem a pessoa é e/ou o que ela quer para sua vida.

Algumas perguntas que ajudam a buscar recursos, valores, habilidades em histórias do passado do/a cliente são: 
- Você consegue se lembrar de algum momento anterior em sua vida no qual você viveu um desafio parecido com o que está vivendo agora e fez algo que te deixou orgulhoso/a?

- O que você fez nessa situação? Como foi para você fazer isso?

- Como você explicaria sua habilidade para ter feito isso?

- Você já tinha feito algo assim antes?

- O que você imagina que você já vinha fazendo que te preparou para esse passo?

- Você sabia, antes de fazer isso, que você era capaz?

- Como você sabia disso?

- O que você acredita que essa ação (o que fez que se sentiu orgulhoso/a no passado) expressa sobre o realmente importa para você?

- Quando você diz que (não é de desistir, por exemplo), o que isso diz sobre você?

- Você pode me contar uma história que realmente ilustra como esse valor está presente na sua vida? Com quem você aprendeu a valorizar isso?

Seguindo o exemplo que citamos anteriormente de uma pessoa que está vivendo uma intensa ansiedade durante a pandemia, a "mão esmagadora de corações", podemos entender, na conversa, que essa mão esmagadora faz com que ela se sinta pessimista e improdutiva, como se estivesse apenas esperando os dias passarem sem fazer nada de útil. Diante disso, podemos perguntar se houve momentos em que essa mão esmagou um pouco menos. Ela nos conta de uma iniciativa de arrecadação de alimentos que seus amigos a convidaram para participar e que, durante os dias engajada com essa atividade, sentiu-se com o coração menos apertado. Dessa conversa, identificamos que um valor importante para essa pessoa é ter uma vida com propósito e que ela aprendeu isso com seu avô, que sempre contava histórias de lutas e conquistas sobre sua família imigrante, por exemplo.

O recontar da história de um momento difícil pode auxiliar no rastreamento de quais ações a pessoa se engajou para enfrentar o problema, bem como quais valores, crenças, intenções e pessoas significativas estavam presentes. Esse movimento pode dar visibilidade a outros entendimentos e oferecer ideias de caminhos que possam ser trilhados no momento atual diante das dificuldades geradas pela pandemia.

O recurso teórico da remembrança pode também ser útil nessa etapa da conversa, permitindo a exploração das contribuições das pessoas significativas que passaram pela vida da pessoa na construção dos valores que ela resgatou a partir da identificação das histórias de exceção. Algumas perguntas ajudam a buscar recursos em relacionamentos significativos das pessoas:

- Quem é a pessoa que teria a certeza de que você vai encontrar formas de lidar com essa situação?

- O que você acha que essa pessoa vê em você (ou nas coisas que você já fez/ faz) que faz com que ela acredite nisso?

- Se a gente perguntasse para essa pessoa qual foi a situação mais difícil que ela acha que você conseguiu superar, qual ela diria?

- Por que acha que ela escolheria essa situação?

- Quem estava presente nesse momento?

- Que coisas colaboraram para que você conseguisse superar?

- Como fulana/o se sentiria se soubesse como te influenciou?

- O que fulano/a diria se estivesse aqui agora?

Nova Perspectiva Sistêmica, v. 29, n. 67, p. 7-22, agosto 2020. 
$\mathrm{Na}$ sequência do exemplo citado, a pessoa resgata outros momentos difíceis que foram superados, identificando a mãe e a melhor amiga como pessoas que acompanharam outras situações, reconhecendo sua determinação e coragem em buscar modos de lidar com as dificuldades e aprender com elas.

\section{ETAPA 4: CONSTRUINDO POSSIBILIDADES FUTURAS}

Nessa etapa, quando o atendimento já se encaminha para o término, o/a terapeuta busca compreender os efeitos da conversa para o/a cliente, verificando se foi útil, resgatando se algo novo foi aprendido e, se for o caso, entendendo quais aprendizados foram esses. A partir disso, constrói-se com o/a cliente como ele/ela pode seguir sua vida com esses novos aprendizados e sentidos.

Neste momento, também é importante conhecermos o que pode desafiar os novos sentidos produzidos pelo/a cliente, antecipando alguns cenários possíveis. Igualmente, buscamos estimular o/a cliente a se conectar com pessoas de sua rede de apoio que possam auxiliar para se lembrar dos recursos, ajudando-o/a a entender que não precisa enfrentar o problema sozinho/a. Todos esses pontos podem colaborar para que os conhecimentos e reflexões realizadas na terapia de sessão única permaneçam vivos.

Para isso, podemos perguntar:

- O que mais te chamou atenção nessa conversa? O que foi mais significativo?

- Como você poderia levar isso para sua vida? Como seria se isso acontecesse?

- Como o problema poderia atrapalhar você de se lembrar do que você viveu hoje?

- O que ajudaria a evitar isso?

- Com quem seria importante você conversar para contar sobre isso tudo que descobrimos nessa conversa?

- Como ela/s/e/s saber/em disso faria a diferença?

- Como ela/s/e/s saber/em disso te ajudaria nos seus próximos passos?

\section{OUTRAS REFERÊNCIAS PARA 0 TRABALHO COM TERAPIA DE SESSÃO ÚNICA}

Gostaríamos rapidamente de mencionar outras iniciativas de produção de conhecimento e atuação na área que valem a pena serem explorados por quem se interessar.

A partir das abordagens breves e focadas na solução, Miller (2011) traz um interessante capítulo sobre o uso de terapia de sessão única em situações de desastres. Mencionamos algumas perguntas que esse trabalho destaca como potentes nos atendimentos nessas situações.

A partir da importância de reconhecermos a necessidade imediata do/a cliente, a primeira pergunta feita para a pessoa é: Qual é a sua maior preocupação nesse momento? Essa autora destaca como útil buscar os recursos não em experiências passadas, como apontamos em nossa abordagem, mas explorar os recursos que já estão sendo utilizados para lidar com a pandemia, como a questão: O que você já tentou fazer para lidar com essa questão?

Para ajudar a pessoa a perceber as possíveis primeiras ações a serem tomadas, o autor sugere: Qual seria a menor mudança que mostraria que as coisas estão caminhando de forma positiva nessa situação? Finalmente, pode-se investir em 
conhecer habilidades ligadas a uma postura de resiliência com relação ao problema, que podem incluir: a existência relacionamentos familiares fortes, criação de sentidos compartilhados sobre a situação com outras pessoas, convicções espirituais, sentimento de esperança, sensação de controle pessoal, criatividade e humor.

A partir de uma postura dialógica, os profissionais do Essential Partners (https:// whatisessential.org/), antigamente nomeado Public Conversations Project, de Boston, EUA, propõem conversas online de terapia de sessão única em grupo na situação da pandemia (Essential Partners, 2020), a partir das perguntas: "Contenos um momento em sua vida em que você encontrou forças ou recursos internos para superar algum desafio" (uma pergunta semelhante à da perspectiva narrativa). Segue-se a essa pergunta o pedido de que cada uma das pessoas compartilhe uma experiência que ajudaria a outras pessoas entenderem como a situação atual do coronavírus o/a está afetando com o destaque daquilo que a pessoa tem como valoroso na sua vida.

Outras perguntas que esses/as profissionais apontam como úteis de serem exploradas são "Que recurso pessoal seu poderia ser um recurso também para outras pessoas?”, "O que precisa de atenção agora que você gostaria de dedicar mais energia?" e "Ao pensar na perturbação causada pela situação atual, quais novas oportunidades para você e para o mundo podem surgir?".

Por fim, indicamos o trabalho das mexicanas Irma Rodriguez (Neca) e Sylvia London, do Grupo Campos Elíseos sobre Terapia sin cita (https://grupocamposeliseos.org/), pronto atendimento em terapia de sessão única sem hora marcada. O trabalho reúne as contribuições da perspectiva de sessão única de Moshe Talmon, da proposta de atendimento na modalidade walk-in de Slive e Bobele (autores norte-americanos autores do livro "Quando tudo o que temos é apenas uma hora” - tradução nossa), das práticas colaborativas e dialógicas de Harlene Anderson, da terapia narrativa de White e Epston, da terapia centrada na solução de Shazer e dos processos reflexivos do Tom Andersen.

\section{REFERÊNCIAS}

Buckley, E. \& Decter, P. (2006). From isolation to community: collaborating with children and families in times of crisis. The International Journal of Narrative Therapy and Community Work, 2. Recuperado de http://www.dulwichcentre.com.

Butler, J. (2015). Quadros de Guerra: quando a vida é passível de luto? Rio de Janeiro: Civilização Brasileira.

Conselho Federal de Psicologia - CFP. (2009). Dispõe sobre a obrigatoriedade do registro documental decorrente da prestação de serviços psicológicos. Brasília, DF: Autor. Recuperado de http://satepsi.cfp.org.br/docs/ResolucaoCFP001-09.pdf

Conselho Federal de Psicologia - CFP. (2018). Regulamenta a prestação de serviços psicológicos realizados por meios de tecnologias da informação e da comunicação e revoga a Resolução CFP n. 11/2012. Brasília, DF: Autor. Recuperado de https:// site.cfp.org.br/wp-content/uploads/2018/05/RESOLU\%C3\%87\%C3\%83ON\%C2\%BA-11-DE-11-DE-MAIO-DE-2018.pdf

Conselho Federal de Psicologia - CFP. (2020). Nota Orientativa às(aos) Psicólogas(os) sobre o trabalho voluntário e Publicidade em Psicologia, diante do Coronavírus (COVID-19). Brasília, DF: Autor. Recuperado de https://www.crpsp.org/ noticia/view/2463/nota-orientativa-asaos-psicologasos-trabalho-voluntario-epublicidade-em-psicologia-diante-do-coronavirus-covid-19 
Conselho Regional de Psicologia de São Paulo - CRP-SP. (2016). Psicologia em emergências e desastres. São Paulo: Autor. Recuperado de https://www.crpsp.org/ uploads/impresso/99/AabX4kwGXX0zM4eJUL-zyRZlcCNCcnmX.pdf

Conselho Regional de Psicologia de São Paulo - CRP-SP. (2020). Em tempos de Covid-19: Tire suas principais dúvidas aqui. São Paulo: Autor. Recuperado de https://www.crpsp.org/noticia/view/2476/ em-tempos-de-covid-19-tire-suas-principais-duvidas-aqui

Drewery, W. \& Winslade, J. (1997). The theoretical story of narrative therapy. In G. Monk, J. Winslade, K. Crocket, \& D. Epston (Eds.), The Jossey-Bass psychology series. Narrative therapy in practice: The archaeology of hope (pp. 32-52). San Francisco, CA: Jossey-Bass.

Essential Parterns. (2020). Resources to lead your own COVID-19 dialogue. Boston: Author.

Foucault, M. (1996). A ordem do discurso. São Paulo: Editora Loyola.

Grandesso, M. A. (2011). "Dizendo olá novamente": a presença de Michael White entre nós, terapeutas familiares. Revista Nova Perspectiva Sistêmica, 20(41), 99-118. Recuperado de http://www.revistanps.com.br/index.php/nps/article/view/208

Hoyt, M. F., Bobele, M., Slive, A., Young, J., \& Talmon, M. (2018). Single-session therapy by walk-in or appointment: Administrative, clinical, and supervisory. Aspectos of one-at-a-time services. New York: Routledge.

Miller, J. K. (2011). Single-session intervention in the wake of hurricane Katrina: Strategies for disaster mental health counseling. In A. Slive \& M. Bobele (Ed.), When one hour is all you have: Effective therapy for walk-in clientes (pp. 185202). Phoenix: Zeig, Tucker, \& Theisen.

Morgan, A. (2007). O que é terapia narrativa? Uma introdução de fácil leitura. Porto Alegre: Centro de Estudos e Práticas Narrativas.

Organização Pan-Americana da Saúde - OPAS. (2015). Primeiros cuidados psicológicos: guia para trabalhadores de campo. Brasília, DF: Autor. Recuperado de https://www. paho.org/bra/index.php?option=com docman\&view=download\&category

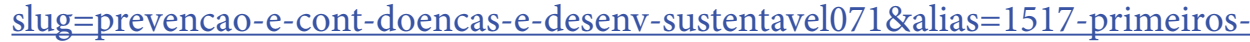
cuidados-psicologicos-um-guia-para-trabalhadores-campo-7\&Itemid=965

Rasera, E. F. \& Japur, M. (2007). Grupo como construção social: aproximações entre construcionismo social e terapia de grupo. São Paulo: Vetor.

Souza, L. V., Lion, C. M., Santos, A. N. M., Figueira, M. R., Patrício, A. A., \& Cavalierí, L. (2018). Aconselhamento Psicológico Narrativo de Sessão única. In Elias et al.. (Orgs.), Formação profissional em psicologia: práticas comprometidas com a comunidade (pp. 63-81). Ribeirão Preto, SP: Sociedade Brasileira de Psicologia.

Talmon, M. (1990). Single session Therapy: Maximizing the Effect of the First (and Often Only). Therapeutic Encounter. São Francisco, CA: Jossey-Bass.

Vicente, A. T., Japur, M., Cesar, A. B. C., Ruffino, C. M. C., \& Russo, R. (2015). The Construction of the Conversational Context of the Group. In E. F. Rasera, (Ed.), Social Constructionist Perspectives on Group Work (pp. 61-70). Taos Institute Publication, USA.

Young, K. (2018) Change in the Winds: The growth of walk-in counseling clinics in Ontario. In M. Hoyt, A. Slive, M. Bobele, J. Young, \& M. Talmon (Eds.), One at a Time: Single Session Therapy by Walk-in or Appointment (pp. 59-71). New York: Routledge Taylor \& Francis Group.

White, M. (2007). Maps of narrative practice. New York: Norton

White, M. (2012). Mapas da prática narrativa. (Migliava, A., trads.). Porto Alegre: Pacartes. White, M. \& Epston, D. (1990). Narrative Means to Therapeutic Ends. New York: WW. Norton. 


\section{LAURA VILELA E SOUZA}

Docente do Departamento de Psicologia e do Programa de Pós-graduação em Psicologia e coordenadora do Dialog - Laboratório de Pesquisa em Práticas Dialógicas e Colaborativas.

https://orcid.org/0000-0003-0732-8175

E-mail: lauravilelasouza@gmail.com

\section{CAMILA MARTINS LION}

Doutoranda em Psicologia FFCLRP, certificação internacional em práticas colaborativas e dialógicas Interfaci/ Houston Galveston Institute/ Taos Institute e Especialista em intervenção familiar sistêmica - FAMERP.

https://orcid.org/0000-0001-6096-6024

E-mail: camila.m.lion@hotmail.com

\section{LETÍCIA TROMBINI VIDOTTO}

Doutoranda e mestra em Psicologia pela FFCLRP, com período sanduíche na Universidade de New Hampshire - EUA. Mediadora de conflitos e facilitadora de diálogos.

https://orcid.org/0000-0002-1367-3074

E-mail: leticiatvidotto@gmail.com

\section{MURILO DOS SANTOS MOSCHETA}

Professor Adjunto do Departamento de Psicologia e do Programa de Pós-graduação em Psicologia e coordenador do grupo de pesquisa DeVerso - sexualidade, saúde e política.

https://orcid.org/0000-0001-7479-2651

E-mail: murilomoscheta@me.com 